\title{
A highly sensitive fluorimetric method for determination of lenalidomide in its bulk form and capsules via derivatization with fluorescamine
}

\author{
Ibrahim A Darwish*, Nasr Y Khalil, Ahmed H Bakheit and Nourh Z Alzoman
}

\begin{abstract}
Background: Lenalidomide (LND) is a potent novel thalidomide analog which demonstrated remarkable clinical activity in treatment of multiple myeloma disease via a multiple-pathways mechanism. The strong evidences-based clinical success of LND in patients has led to its recent approval by US-FDA under the trade name of Revlimid ${ }^{\circledR}$ capsules by Celgene Corporation. Fluorimetry is a convenient technique for pharmaceutical quality control, however there was a fluorimetric method for determination of LND in its bulk and capsules.

Results: A novel highly sensitive and simple fluorimetric method has been developed and validated for the determination of lenalidmide (LND) in its bulk and dosage forms (capsules). The method was based on nucleophilic substitution reaction of LND with fluorescamine (FLC) in aqueous medium to form a highly fluorescent derivative that was measured at $494 \mathrm{~nm}$ after excitation at $381 \mathrm{~nm}$. The factors affecting the reaction were carefully studied and optimized. The kinetics of the reaction was investigated, and the reaction mechanism was postulated. Under the optimized conditions, linear relationship with good correlation coefficient (0.9999) was found between the fluorescence intensity and LND concentration in the range of $25-300 \mathrm{ng} / \mathrm{mL}$. The limits of detection and quantitation for the method were 2.9 and $8.7 \mathrm{ng} / \mathrm{mL}$, respectively. The precision of the method was satisfactory; the values of relative standard deviations did not exceed $1.4 \%$. The proposed method was successfully applied to the determination of LND in its bulk form and pharmaceutical capsules with good accuracy; the recovery values were $97.8-101.4 \pm 1.08-2.75 \%$.
\end{abstract}

Conclusions: The proposed method is selective and involved simple procedures. In conclusion, the method is practical and valuable for routine application in quality control laboratories for determination of LND.

Keywords: Lenalidomide, Fluorescamine, Flourimetry, Pharmaceutical analysis

\section{Background}

Lenalidomide (LND) is a potent novel thalidomide analog which demonstrated remarkable clinical activity in treatment of multiple myeloma disease [1-5] via a multiple-pathways mechanism [6-9]. The strong evidencesbased clinical success of LND in patients has led to its recent approval by US-FDA under the trade name of Revlimid $^{\otimes}$ capsules by Celgene Corporation [10]. LND has an improved side effects profile than its parent

\footnotetext{
* Correspondence: idarwish@ksu.edu.sa

Department of Pharmaceutical Chemistry, College of Pharmacy, King Saud University "P.O. Box 2457, Riyadh 11451, Saudi Arabia
}

compound thalidomide [11]. These side effects can be managed by combination therapy and/or careful dose adjustment [12]. The therapeutic benefits profile of LND is anticipated to encourage the development of new pharmaceutical preparations for LND. As a consequence, there is an increasing demand for proper analytical technologies for quality assurance of LND formulations.

Few methods have been reported for the determination LND in bulk material and in capsules. These methods included two spectrophotometric methods [13]. The first method was based on diazo-coupling reaction with $\mathrm{N}-(1-$ napthyl) ethylenediamine dihydrochloride and the second
() ChemistryCentral

(c) 2012 Darwish et al.; licensee Chemistry Central Ltd. This is an Open Access article distributed under the terms of the Creative Commons Attribution License (http://creativecommons.org/licenses/by/2.0), which permits unrestricted use, distribution, and reproduction in any medium, provided the original work is properly cited. 
method was based on the formation of a colored condensation product with $\mathrm{p}$-dimethylaminocinnamaldehyde. In addition, two HPLC methods have reported for analysis of bulk material of LND and its related impurities [14] and capsules [15]. These methods were associated with some major drawbacks such as lack of selectivity, timeconsumption and/or use of expensive instruments.

Fluorimetry is considered one of the most convenient analytical techniques, because of its inherent simplicity, high sensitivity, low cost, and wide availability in most quality control laboratories. No attempt has yet been made for the fluorimetric determination of LND. The present study describes, for the first time, the development of a novel highly sensitive and simple fluorimetric method for the determination of LND in its bulk form and capsules. The method was based on the derivatization of LND with fluorescamine (FLC) in aqueous medium to produce a highly fluorescent product that was measured fluorimetrically at $494 \mathrm{~nm}$ after excitation at $381 \mathrm{~nm}$.

\section{Experimental Apparatus}

Fluorescence measurements were carried out on a RF5301 PC spectrofluorimeter (Shimadzu Corporation Kyoto, Japan) equipped with a $150 \mathrm{~W}$ xenon lamp and $1 \mathrm{~cm}$ quartz cells. The slit widths of both the excitation and emission monochromators were set at $1.5 \mathrm{~nm}$. The calibration and linearity of the instrument were frequently checked with standard quinine sulphate. $\mathrm{pH}$ meter Model 211 a product of HANNA Instruments Inc. (Smithfield, RI, USA).

\section{Reagents and materials}

Lenalidomide (LND), free base (3-(4'-aminoisoindoline1 '-one)-1-piperidine-2,6-dione) (LC Laboratories ${ }^{\circledR}$, Woburn, MA, USA ) was obtained and used as received; its purity was $100.2 \pm 1.25 \%$. Fluorescamine (FLC; Sigma Chemical Co., St. Louis, USA) was prepared in acetonitrile to contain $0.025 \%(\mathrm{w} / \mathrm{v})$; the solution could be used for seven days when kept in the refrigerator. Revlimid capsules (Celgene Corporation, New Jersy, USA) labeled to contain $5 \mathrm{mg}$ LND per capsule was obtained from the local market. Double distilled water was obtained through WSC-85 water purification system (Hamilton Laboratory Glass Ltd., Kent, USA), and used throughout the work. All other solvents and materials used throughout this study were of analytical grade.

\section{Preparation of standard and sample solutions Lenalidomide standard solution}

An accurately weighed amount ( $25 \mathrm{mg}$ ) of LND was quantitatively transferred into a $25-\mathrm{mL}$ calibrated flask, dissolved in $20 \mathrm{~mL}$ methanol, completed to volume with the same solvent to obtain a stock solution of $1 \mathrm{mg} / \mathrm{mL}$. This stock solution was further diluted with water to obtain a working stock solution containing $0.5 \mu \mathrm{g} / \mathrm{mL}$.

\section{Capsules sample solution}

The contents of 20 Revlimid $^{\circledR}$ capsules (Celgene Corporation, NJ, USA), labeled to contain $5 \mathrm{mg}$ of LEN per capsule were evacuated and weighed. An accurately weighed portion equivalent to $50 \mathrm{mg}$ of LND was transferred into a $50-\mathrm{mL}$ calibrated flask containing $\sim 40 \mathrm{~mL}$ of methanol. The contents of the flask were swirled, sonicated for $5 \mathrm{~min}$, and then completed to volume with methanol. The contents were mixed well and filtered rejecting the first portion of the filtrate. The prepared solution was diluted quantitatively with distilled water to obtain a suitable concentration for the analysis.

\section{General recommended procedure}

Accurately measured aliquots of LND working stock solution $(0.5 \mu \mathrm{g} / \mathrm{mL})$ were transferred into separate $10-\mathrm{mL}$ calibrated flasks to obtain a series of LND standard solutions covering the working range of $25-300 \mathrm{ng} / \mathrm{mL}$ in the final solution. One milliliter of FLC solution $(0.025 \% \mathrm{w} / \mathrm{v})$ was added to each flask. The reaction was allowed to proceed at room temperature $\left(25 \pm 2^{\circ} \mathrm{C}\right)$ for $10 \mathrm{~min}$, and then completed to volume with water. The fluorescence intensity of the resulting solutions were measured at $494 \mathrm{~nm}$ after excitation at $381 \mathrm{~nm}$ against a reagent blank prepared in the same manner but using water instead of the LND working stock solution.

\section{Determination of stoichiometric ratio}

The Job's method of continuous variation [16] was employed. Master equimolar $\left(1.5 \times 10^{-5} \mathrm{M}\right)$ aqueous solutions of LND and FLC were prepared. Series of $10-\mathrm{mL}$ portions of the master solutions of LND and FLC were made up comprising different complementary proportions $(0: 10,1: 9, \ldots, 9: 1,10: 0$, inclusive) in $10-\mathrm{mL}$ calibrated flasks and the reactions were allowed to proceed for $10 \mathrm{~min}$. The solutions were further manipulated and the fluorescence signals were measured as described under the general recommended procedure.

\section{Results and discussion}

\section{Excitation and emission spectra}

Because of the absence of native fluorescence of LND, its derivatization with fluorogenic reagent was necessary for its fluorimetric determination. FLC was chosen as a derivatizing reagent because it forms highly fluorescent derivatives with primary amines under relatively mild reaction conditions [17]. It was found that LND reacts with FLC and forms a highly fluorescent derivative that exhibited maximum fluorescence intensity $(\lambda \mathrm{em})$ at $494 \mathrm{~nm}$ after excitation at wavelength ( $\lambda$ ex) of $381 \mathrm{~nm}$. 
The excitation and emission spectra for the reaction product of LND with FLC are given in Figure 1.

\section{Optimization of reaction variables \\ Effect of FLC concentration}

The study of the reaction between LND and FLC revealed that the reaction was dependent on the FLC concentration as the relative fluorescence intensity (RFI) of the reaction mixture increased steadily as the FLC concentration increased up to a final concentration of $0.002 \%$, w/v (Figure 2). Beyond this concentration, the slope of the curve significantly decreased. For more precise readings, a concentration of $0.025 \%(\mathrm{w} / \mathrm{v})$ of FLC reagent solution was used throughout the further experiments.

\section{Effect of $\mathrm{pH}$}

The effect of the $\mathrm{pH}$ on the reaction was studied by carrying out the reaction in borate buffer solution in the $\mathrm{pH}$ range of 6.5-9.5. The results indicated that the RFI increased initially as the $\mathrm{pH}$ increased and maximum readings were attained at $\mathrm{pH} 7.0 \pm 0.2$ (Figure 3 ). In previous studies involving FLC as a fluorofore, the maximum readings were obtained at $\mathrm{pH}$ around 8.0 [18]. This was possibly due to the predominance of the free amino group of the investigated substance rather than its salt form in acidic $\mathrm{pH}$. Consequently, this facilitates the nucleophilic substitution reaction. In the present study, such alkaline $\mathrm{pH}$ was not necessary because the LND is already in the form of free base. Furthermore, at higher $\mathrm{pH}$ values, sharp decrease in the readings occurred (Figure 3). This was probably attributed to the hydrolysis of the reaction product between LND and FLC in alkaline medium. Neutral $\mathrm{pH}$ was found to be optimum for the reaction between LND and FLC. Distilled water was compared with borate buffer of $\mathrm{pH} \mathrm{7,} \mathrm{and} \mathrm{similar} \mathrm{results} \mathrm{were} \mathrm{obtained.} \mathrm{Therefore,}$

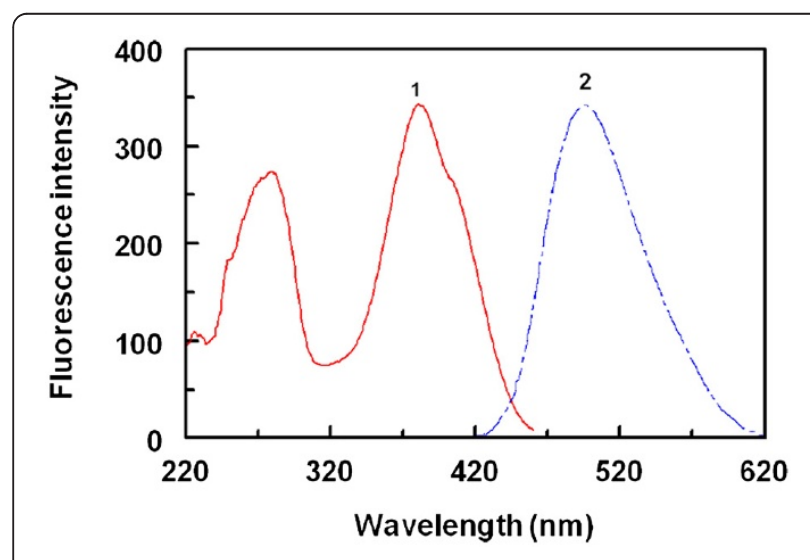

Figure 1 Excitation (1) and emission (2) spectra of the reaction product of LND $(275 \mathrm{ng} / \mathrm{mL})$ with FLC $(0.025 \%$, w/v).

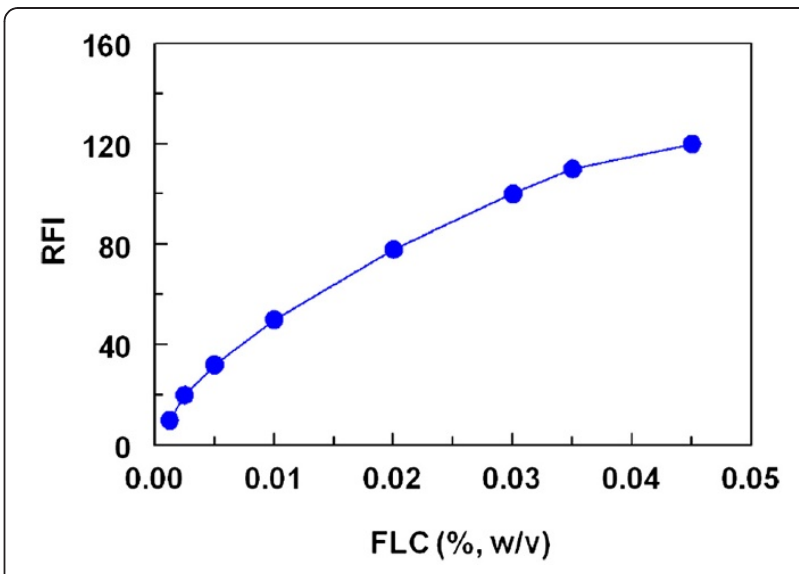

Figure 2 Effect of FLC concentration on its reaction with LND $(75 \mathrm{ng} / \mathrm{mL})$.

the reactions in all the subsequent experiments were carried out in distilled water. This was in favor of the simplicity of the proposed procedure, and environmental and health safety.

\section{Effect of time}

In order to determine the optimum time required for completion of the reaction, the derivatization reaction was carried out at room temperature $\left(25 \pm 2^{\circ} \mathrm{C}\right)$ and the induced fluorescence signals were measured immediately after the addition of FLC and monitored for $30 \mathrm{~min}$. The optimum reaction time was considered as the time at which the highest fluorescence signals with reproducible results are obtained in a comfortable measurement region on the FI-time curve (wide plateau). The results indicated that the reaction was very fast and almost completed within $5 \mathrm{~min}$ (Figure 4). Beyond this time, the RFI values did not change by time. For comfortable

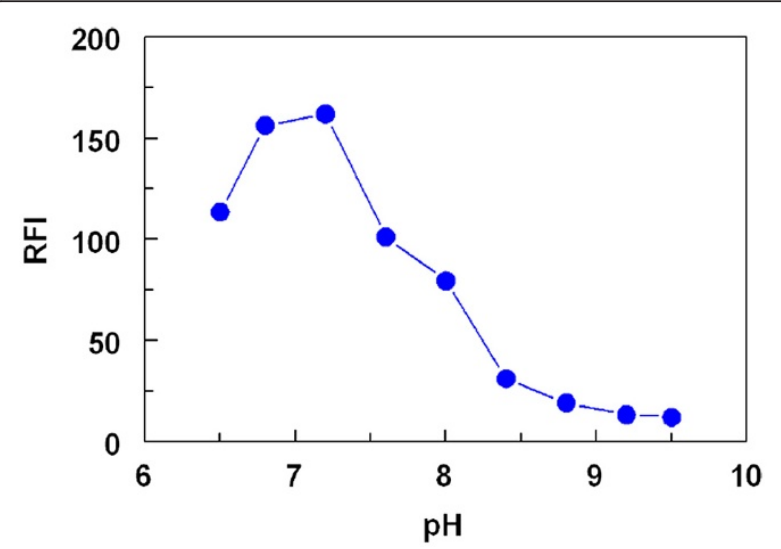

Figure 3 Effect of $\mathrm{pH}$ on the reaction of $\mathrm{FLC}(0.025 \%$, w/v) with LND $(130 \mathrm{ng} / \mathrm{mL})$. 


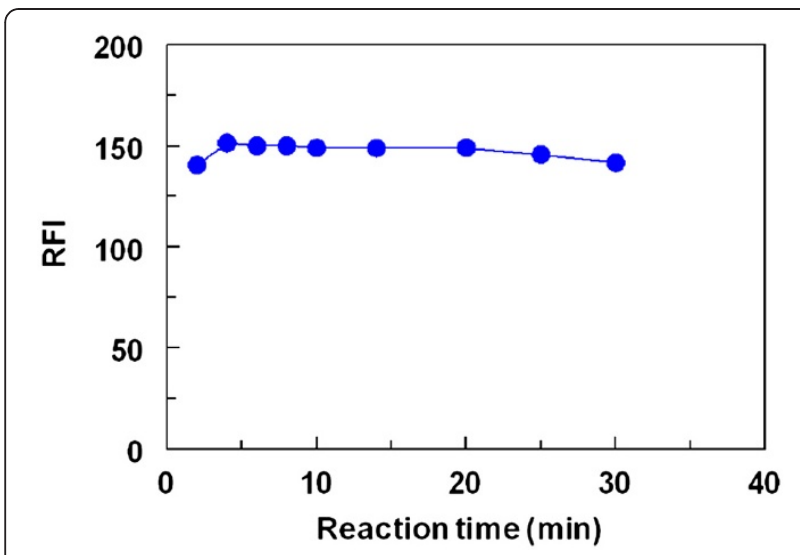

Figure 4 Effect of time on the reaction of $\operatorname{FLC}(0.025 \%$, w/v) with LND (130 $\mathrm{ng} / \mathrm{mL})$.

readings with high precise results, all the subsequent reactions were carried out for $10 \mathrm{~min}$.

\section{Effect of diluting solvent}

In order to select the most suitable diluting solvents for the formation and stability of the reaction product, different solvent were investigated. These solvents were: water, methanol, ethanol, and acetonitrile. The highest fluorescence intensities were obtained when water was used as a diluting solvent (Figure 5).

\section{Stability of the fluorescent derivative}

The effect of time on the stability of the LND-FLC fluorescent derivative was studied by monitoring the fluorescence intensities of the reaction solution (after dilution) at different time intervals. It was found that the RFI values remain constant for at least 1 hour. This allowed the processing of large batches of samples, and their comfortable measurements with convenience. This

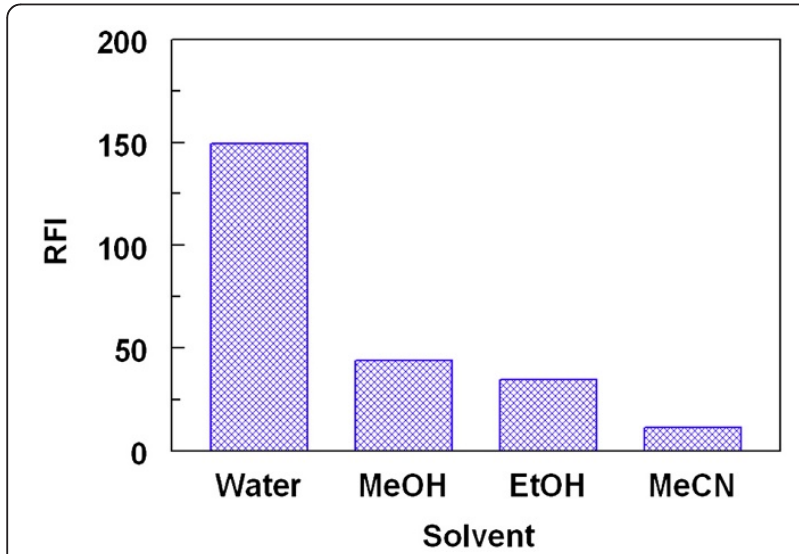

Figure 5 Effect of diluting solvent on the reaction between LND $(130 \mathrm{ng} / \mathrm{mL})$ and FLC $(0.025 \%$, w/v). Solvents were: water, methanol $(\mathrm{MeOH})$, ethanol $(\mathrm{EtOH})$, and acetonitrile (MeCN).
Table 1 Optimization of variables affecting the reaction of LND with FLC

\begin{tabular}{lll}
\hline Variable & Studied range & Optimum condition \\
\hline FLC conc. $(\%, w / v)$ & $0.00025-0.0045$ & 0.0025 \\
\hline $\mathrm{pH}$ & $6.5-9.5$ & $7 \pm 0.2$ \\
\hline Reaction time $(\mathrm{min})$ & $2-30$ & 10 \\
\hline Solvent & Different $^{\text {a }}$ & Water \\
\hline Stability of LND-FLC $(\mathrm{min})$ & $10-60$ & $10-60$ \\
\hline Excitation wavelength, $\lambda_{\text {ex }}(\mathrm{nm})$ & $220-460$ & 381 \\
\hline Emission wavelength, $\lambda_{\text {em }}(\mathrm{nm})$ & $420-620$ & 494 \\
\hline
\end{tabular}

a Solvents tested: Water, methanol, ethanol, and acetonitrile.

${ }^{b}$ The stability of the LND-FLC was studied after dilution of the reaction solution.

increased the convenience of the method as well as made it applicable for large number of samples in quality control laboratories.

A summary for the optimization of the variables affecting the reaction of LND with FLC is given in Table 1.

\section{Stoichiometry, kinetics and mechanism of the reaction}

Under the optimum conditions (Table 1), the stoichiometry of the reaction between LND and FLC was investigated by Job's method [16]. The symmetrical bell-shape of Job's plot (Figure 6) indicated that the LND:FLC ratio was $1: 1$. Based on this ratio, the reaction pathway was postulated to be proceeded as shown in Figure 7.

Under the optimum conditions (Table 1), the RFI-time curves for the reaction at varying LND concentrations $\left.\left(1.93 \times 10^{-7}-1.16 \times 10^{-6} \mathrm{M}\right)\right]$ with a fixed concentration of FLC $\left.\left[9 \times 10^{-5} \mathrm{M}\right)\right]$ were generated (Figure 8 ). The initial reaction rates $(\mathrm{K})$ were determined from the slopes of these curves. The logarithms of the reaction rates ( $\log \mathrm{K})$ were plotted as a function of logarithms of LND concentrations $(\log \mathrm{C})$; Figure 9. The regression analysis

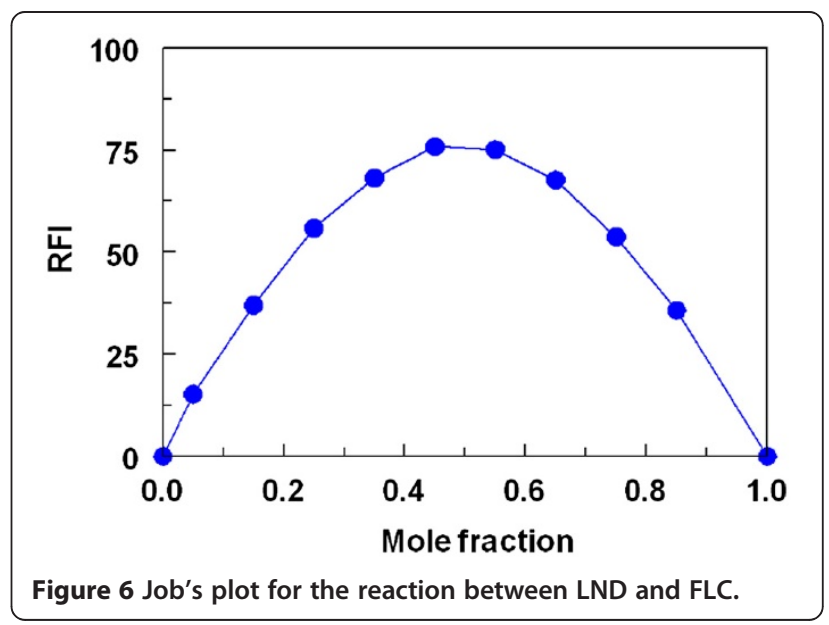




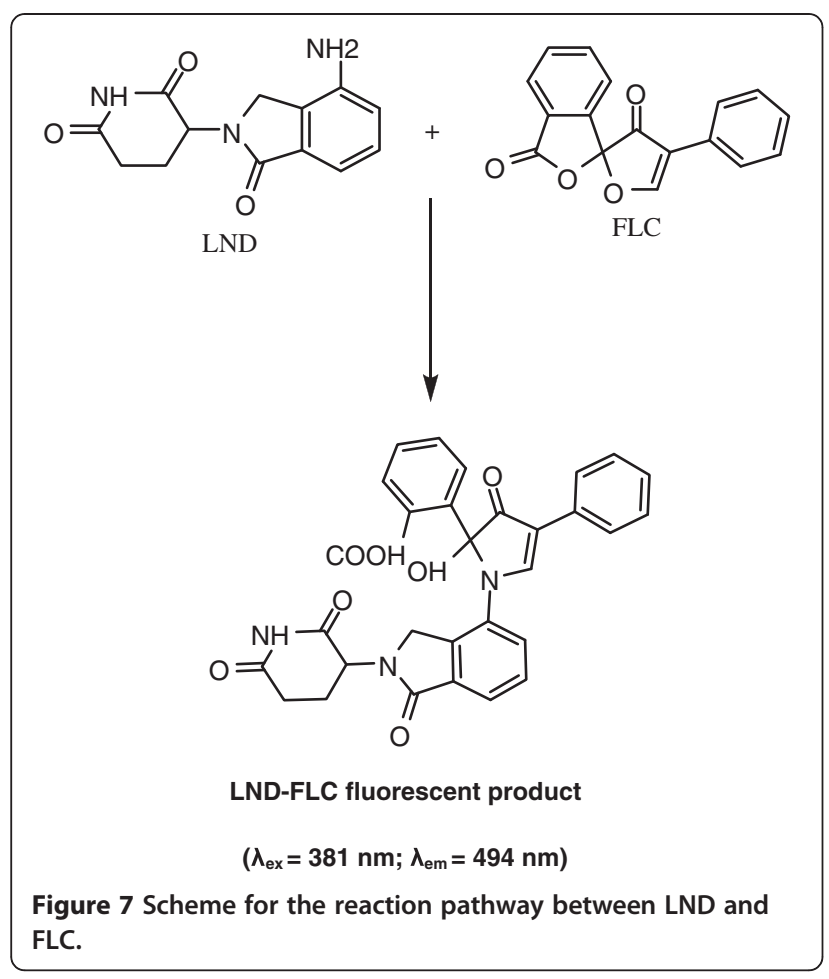

for the values was performed by fitting the data to the following equation:

$$
\log \mathrm{K}=\log \mathrm{K} \prime+n \log C
$$

where $\mathrm{K}$ is reaction rate, $K \prime$ is the rate constant, $C$ is the molar concentration of LND, and $n$ (slope of the regression line) is the order of the reaction. As seen in Figure 9, a straight line with slope values of $0.9946(\approx 1)$ confirming that the reaction was first order. However under the optimized reaction conditions, the concentration of FLC

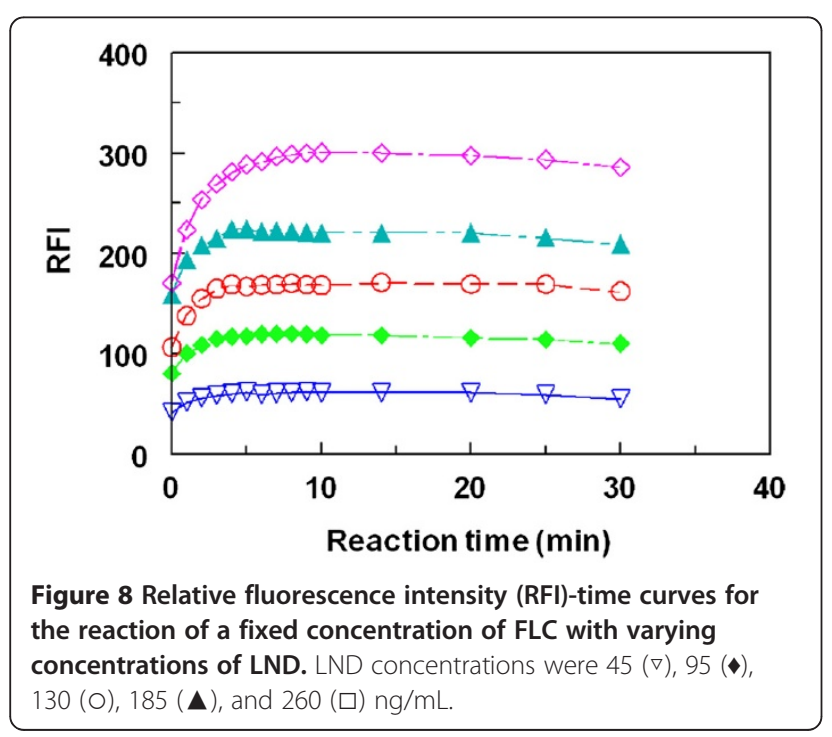

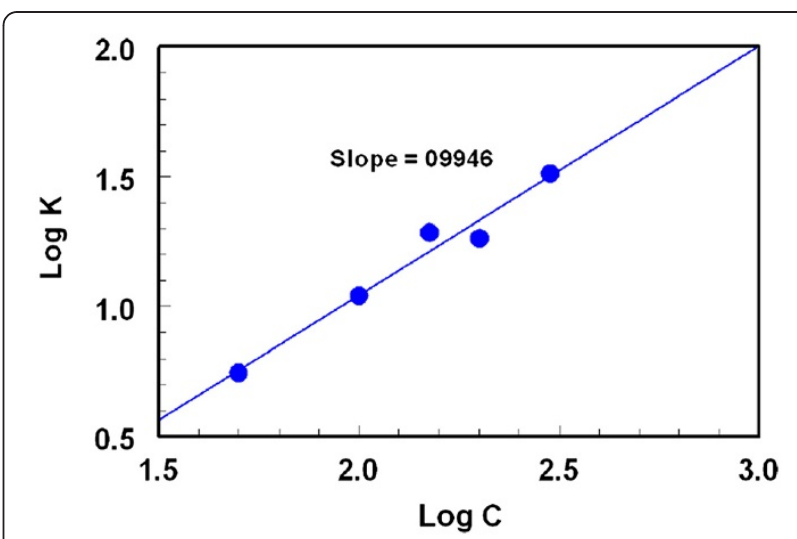

Figure 9 Linear plot for Log $C$ versus Log $\mathrm{K}$ for the kinetic reaction of LND and FLC.

was in much more excess than that of LND in the reaction solution. Therefore, the reaction was regarded as a pseudo-first order reaction.

\section{Validation of the method}

\section{Calibration and sensitivity}

Under the optimum conditions (Table 1), calibration curve for the determination of LND by its reaction with FLC was constructed by plotting the RFI as a function of the corresponding LND concentration. The regression equation for the results was: $\mathrm{RFI}=\mathrm{a}+\mathrm{bC}$, where RFI is the relative fluorescence intensity, $\mathrm{C}$ is the concentration of LND in $\mathrm{ng} / \mathrm{mL}$. Linear relationship with small intercept and excellent correlation coefficient $(r=0.9999)$ was obtained in the range of $25-300 \mathrm{ng} / \mathrm{mL}$. The limit of detection (LOD) and limit of quantification (LOQ) were determined according to $\mathrm{ICH}$ guidelines for validation of analytical procedures [19]. The LOD and LOQ values were found to be 2.9 and $8.7 \mathrm{ng} / \mathrm{mL}$, respectively. The parameters for the analytical performance of the proposed fluorimetric method are summarized in Table 2.

Table 2 Statistical parameters for the determination of LND by the proposed fluorimetric method based on its reaction with FLC

\begin{tabular}{ll}
\hline Parameter & Value \\
\hline Linear range $(\mathrm{ng} / \mathrm{mL})$ & $25-300$ \\
Intercept & 11.8 \\
SD of intercept & 0.921 \\
Slope & 1.047 \\
SD of slope & 0.0054 \\
Correlation coefficient $(\mathrm{r})$ & 0.9999 \\
LOD $(\mathrm{ng} / \mathrm{mL})$ & 2.9 \\
LOQ $(\mathrm{ng} / \mathrm{mL})$ & 8.7 \\
\hline
\end{tabular}


Table 3 Recovery studies for determination of LND by the proposed fluorimetric method based on its reaction with FLC

\begin{tabular}{ll}
\hline Taken $(\mathbf{n g} / \mathbf{m L})$ & Recovery $(\% \pm \mathrm{SD})^{\mathbf{a}}$ \\
\hline 100 & $98.5 \pm 2.54$ \\
150 & $97.8 \pm 2.02$ \\
200 & $100.1 \pm 1.24$ \\
250 & $99.5 \pm 2.75$ \\
300 & $101.4 \pm 1.08$ \\
& Average $99.46 \pm 1.40$ \\
\hline
\end{tabular}

${ }^{a}$ Values are mean of three determinations.

\section{Accuracy and precision}

The accuracy and precision of the proposed fluorimetric method was determined by replicate analysis of five different concentrations of the working standard. The recovery values were $97.8-101.4 \pm 1.08-2.75 \%$ (Table 3 ), indicating the accuracy of the proposed method. The average recovery from all the concentrations was found to be $99.5 \%$ with SD of $1.40 \%$ indicating the good accuracy and reproducibility of the results. Furthermore intraand inter-day precisions for determination of LND in bulk powder were assessed at three varying LND concentrations (low, medium, and high). The average recovery values were 101.40 and $102.27 \%$ with RSD values of 1.13 and $2.29 \%$ for intra- and inter-assay precision, respectively (Table 4). These good recovery values and low RSD values revealed the high accuracy and precisions, respectively.

\section{Robustness and ruggedness}

Robustness was examined by evaluating the influence of small variation in the method variables on its analytical performance. In these experiments, one parameter was changed whereas the others were kept unchanged, and the recovery percentage was calculated each time. It was found that variation in the FLC concentrations (0.02$0.03 \%, w / v)$, temperature (optimum $\left.\pm 2{ }^{\circ} \mathrm{C}\right), \mathrm{pH}(6.8-$ 7.2 ) and time (optimum $\pm 5 \mathrm{~min}$ ) did not significantly affect the recovery values. The most critical factor affecting the results was the FLC concentration and therefore it had to be added accurately to attain a fixed concentration in all the solutions. Ruggedness was also tested by applying the method to the assay of LND using fixed operational conditions within $\pm 10 \%$ changes and on different days. The results were reproducible and the RSD\% did not exceed $2.29 \%$.

\section{Practical applications of the proposed method}

It is evident from the above-mentioned results that the proposed method gave satisfactory results with LND in bulk form. Also the pharmaceutical dosage forms (Revlimid $^{\circledR}$ capsules) were analyzed for their LND content by the proposed method. The percentage found from the label claim was $100.11 \pm 1.61 \%$ of the label claim, indicating the successful applicability of the proposed method in quality control laboratories for determination of LND. The results obtained by the proposed method was compared with those obtained by a reported method [15] with respect to the accuracy (by t-test), and precision (by F-test). It was found that the calculated $\mathrm{t}$ - and F-values were lower than the tabulated ones. This indicated that there were no significant differences between the means and variance between the two methods in terms of the accuracy and precision.

\section{Advantages of the proposed method over the reported methods}

This study represents the first report describing the successful evaluation of FLC as an analytical reagent in the development of a highly sensitive and simple fluorimetric method for the quantitative determination of LND. The proposed method is superior to the previously reported spectrophotometric methods in terms of the sensitivity and simplicity of the derivatization procedures. As well, the proposed procedure used water as a green, inexpensive, and safe solvent, rather than the costive and toxic organic solvents that have been employed in the previously reported HPLC methods. In addition, the method employed a simple inexpensive fluorimeter that is available in most quality control laboratories, rather than the expensive HPLC systems.

Table 4 Intra-assay and inter-assay precision and accuracy for determination of LND by the proposed fluorimetric method

\begin{tabular}{|c|c|c|c|c|}
\hline \multirow{2}{*}{$\begin{array}{l}\text { Nominal } \\
\text { conc. } \\
\text { (ng/mL) }\end{array}$} & \multicolumn{2}{|c|}{ Intra-assay } & \multicolumn{2}{|c|}{ Inter-assay } \\
\hline & Measured conc. (ng/mL) & ${\overline{\text { Recovery }}(\% \pm \mathrm{RSD})^{\mathrm{a}}}$ & Measured conc. (ng/mL) & Recovery (\% \pm RSD) ${ }^{b}$ \\
\hline 25 & 25.60 & $102.40 \pm 2.86$ & 26.10 & $104.44 \pm 0.69$ \\
\hline 100 & 100.56 & $100.56 \pm 0.67$ & 102.50 & $102.50 \pm 2.23$ \\
\hline \multirow[t]{2}{*}{300} & 310.50 & $100.35 \pm 0.68$ & 299.6 & $99.87 \pm 0.39$ \\
\hline & Average & $101.10 \pm 1.13$ & Average & $102.27 \pm 2.29$ \\
\hline
\end{tabular}

\footnotetext{
a Values are mean of five determinations.
}

b Values are mean of four determinations. 


\section{Conclusions}

A novel simple and sensitive fluorimetric method for the determination of LND in bulk form and capsules has been successfully developed and validated. The method involved simple derivatization of LND with FLC reagent, and subsequent measurement of the fluorescence intensity of the fluorescent reaction product. The proposed method is specific, accurate, reproducible, and highly sensitive to be applied on the analysis of bulk form and capsules. Furthermore, the analysis requires a simple apparatus, thus the proposed method is suitable for routine analysis of LND in quality control laboratories.

\section{Abbreviations}

LND: Lenalidomide; FLC: Fluorescamine; $\lambda_{\text {ex }}$ Excitation wavelength; $\lambda_{\text {em }}$ : Emission wavelength; RFI: Relative fluorescence intensity; ICH: The international Conference on Harmonization; LOD: Limit of detection; LOQ: Limit of quantification; SD: Standard deviation; RSD: Relative standard deviation.

\section{Competing interests}

The authors declare that they have no conflict of interests.

\section{Authors' contributions}

IAD proposed the subject, designed the study, participated in the results discussion and revised the manuscript. NYK participated in the assay design, conducted the validation of the assay, and participated in preparing the manuscript. AHB conducted the optimization of the assay conditions and prepared the draft version of the manuscript. NZA participated in study design, literature review, assay validation and preparing the manuscript. All authors read and approved the final manuscript.

\section{Acknowledgments}

The authors extend their appreciation to the Deanship of Scientific Research at King Saud University for funding the work through the research group project No. RGP-VPP-203.

Received: 1 October 2012 Accepted: 11 October 2012

Published: 16 October 2012

\section{References}

1. Tariman JD: Lenalidomide: a new agent for patients with relapsed or refractory multiple myeloma. Clin. J. Oncol. Nursing 2007, 11:569-574.

2. Sonneveld P, Palumbo A: Lenalidomide: a new therapy for multiple myeloma. EJHPP 2008, 14:58-61.

3. Shah SR, Tran TM: Lenalidomide in myelodysplastic syndrome and multiple myeloma. Drugs 2007, 67:1869-1881.

4. Falco P, Cavallo F, Larocca A, Liberati AM, Musto P, Boccadoro M, Palumbo $\mathrm{A}$ : Lenalidomide and its role in the management of multiple myeloma. Expert Rev Anticancer Ther 2008, 8:865-874.

5. Hideshima T, Richardson PG, Anderson KC: Current therapeutic uses of lenalidomide in multiple myeloma. Expert Opinion on Invest. Drugs 2006, 15:171-179.

6. Corral LG, Haslett PA, Muller GW, Chen R, Wong LM, Ocampo CJ, Patterson RT, Stirling DI, Kaplan G: Differential cytokine modulation and T cell activation by two distinct classes of thalidomide analogues that are potent inhibitors of TNF-alpha. J Immunol 1999, 163:380-386.

7. Anderson KC: Lenalidomide and thalidomide: mechanisms of action-similarities and differences. Seminars Hematol. 2005, 42:S3-58.

8. Richardson P, Anderson K: Immunomodulatory analogs of thalidomide: an emerging new therapy in myeloma. J Clin Oncol 2004, 22:3212-3214.

9. Verhelle D, Corral LG, Wong K, Mueller JH, Parseval LM, Pergakes KJ, Schafer PH, Chen R, Glezer E, Ferguson GD, Lopez-Girona A, Muller GW, Brady HA, Chan KWH: Lenalidomide and CC-4047 inhibit the proliferation of malignant B cells while expanding normal CD34+ progenitor cells. Cancer Res 2007, 67:746-755.
10. Celgene Corporation: Revlimid ${ }^{\text {B }}$ in combination with dexamethasone SNDA granted approval by FDA for treatment of multiple myeloma. http://ir.celgene. com/phoenix.zhtml?c=111960\&p=irol-newsArticle\&lD=877894\&highlight.

11. Rao KV: Linalidomide in the treatment of multiple myeloma. Am. J. Health System Pharmacists 2007, 64:1799-1807.

12. Palumbo A, Falco P, Corradini P, Falcone A, Di Raimondo F, Giuliani N, Ciccone CCG, Omedè P, Ambrosini MT, Gay F, Bringhen S, Musto P, Foà R, Knight R, Zeldis JB, Boccadoro M, Petrucci MT: Melphalan, prednisone, and lenalidomide treatment for newly diagnosed myeloma: a report from the gimema-Italian multiple myeloma network. J. Clin. Oncol 2007, 25:4459-4465.

13. Sastry BS, Gananadhamu S, Prasad SVS, Venu GRK: New spectrophotometric methods for estimation of lenalidomide in pharmaceutical formulations. Int. J. PharmTech Res. 2009, 1:416-419.

14. Saravanan G, Rao BM, Ravikumar M, Suryanarayana MV, Someswararao N, Acharyulu PVR: Development of an HPLC assay method for lenalidomide. Chromatographia 2007, 66:287-290.

15. Maheswara RL, Janardhan RK, Bhaskar RL, Raveendra Reddy P: Development of a rapid and sensitive HPLC assay method for lenalidomide capsules and its related substances. E-J. Chem 2012, 9:1165-1174.

16. Job P: Advanced Physicochemical Experiments. 2nd edition. Edinburgh: Oliner and Boyd; 1964:54.

17. Toyo'oka T: Modern Derivatization Methods for Separation Sciences. Chichester: John Wiley and Sons Inc; 1999:103-106.

18. Belal F, Abdine H, Almajed A, Khalil NY: Spectrofluorometric determination of vigabatrin and gabapentin in urine and dosage forms through derivatization with fluorescamine. J Pharm Biomed Anal 2002, 27:253-260.

19. ICH Guideline, Q2(R1): Validation of analytical procedures: text and methodology. London: The International Conference on Harmonization; 2005.

doi:10.1186/1752-153X-6-118

Cite this article as: Darwish et al:: A highly sensitive fluorimetric method for determination of lenalidomide in its bulk form and capsules via derivatization with fluorescamine. Chemistry Central Journal 2012 6:118.

Publish with ChemistryCentral and every
scientist can read your work free of charge
"Open access provides opportunities to our
colleagues in other parts of the globe, by allowing
anyone to view the content free of charge."
W. Jeffery Hurst, The Hershey Company.
- available free of charge to the entire scientific community
- peer reviewed and published immediately upon acceptance
- cited in PubMed and archived on PubMed Central
- yours - you keep the copyright
Submit your manuscript here:
http://www.chemistrycentral.com/manuscript/

